\title{
Atmospheric correction of thermal-infrared imagery of the 3-D urban environment acquired in oblique viewing geometry
}

\author{
F. Meier ${ }^{1}$, D. Scherer ${ }^{1}$, J. Richters ${ }^{2}$, and A. Christen ${ }^{3}$ \\ ${ }^{1}$ Technische Universität Berlin, Department of Ecology, Chair of Climatology, Rothenburgstraße 12, 12165 Berlin, Germany \\ ${ }^{2}$ Lohmeyer Consulting Engineers GmbH \& Co. KG, Karlsruhe, Germany \\ ${ }^{3}$ University of British Columbia, Department of Geography \& Atmospheric Science Program, Vancouver, Canada
}

Received: 7 October 2010 - Published in Atmos. Meas. Tech. Discuss.: 13 December 2010

Revised: 21 April 2011 - Accepted: 2 May 2011 - Published: 20 May 2011

\begin{abstract}
This research quantifies and discusses atmospheric effects, which alter the radiance observed by a ground-based thermal-infrared (TIR) camera. The TIR camera is mounted on a boom at a height of $125 \mathrm{~m}$ above ground on top of a high-rise building in the city of Berlin, Germany $\left(52.4556^{\circ} \mathrm{N}, 13.3200^{\circ} \mathrm{E}\right)$ and observes the Earth's surface. The study shows that atmospheric correction of TIR imagery of the three-dimensional (3-D) urban environment acquired in oblique viewing geometry has to account for spatial variability of line-of-sight (LOS) geometry. We present an atmospheric correction procedure that uses these spatially distributed LOS geometry parameters, the radiative transfer model MODTRAN ${ }^{\mathrm{TM}} 5.2$ and atmospheric profile data derived from meteorological measurements in the field of view (FOV) of the TIR camera. The magnitude of atmospheric effects varies during the analysed 24-hourly period (6 August 2009) and is particularly noticeable for surfaces showing a strong surface-to-air temperature difference. The differences between uncorrected and corrected TIR imagery reach up to $6.7 \mathrm{~K}$ at 12:00. The use of non-spatially distributed LOS parameters leads to errors of up to $3.7 \mathrm{~K}$ at $12: 00$ and up to $0.5 \mathrm{~K}$ at $24: 00$.
\end{abstract}

\section{Introduction}

Surface temperature is a key variable in the study of energy and mass exchange at the surface-atmosphere interface. The combination of natural and anthropogenic threedimensional (3-D) objects in urban areas results in strong spatial and temporal heterogeneity of surface temperatures of urban facets (Voogt and Oke, 1998; Lagouarde and Irvine,

Correspondence to: F. Meier

(fred.meier@tu-berlin.de)
2008; Lagouarde et al., 2010). Thermal-infrared (TIR) remote sensing approaches, which allow the derivation of surface temperatures, have been widely applied in urban climate studies (Voogt and Oke, 2003; Weng, 2009) and were part of several integrated field campaigns like BUBBLE (Rotach et al., 2005), ESCOMPOTE (Mestayer et al., 2005) and CAPITOUL (Masson et al., 2008).

With respect to urban climate research, low cost and highresolution TIR camera systems mounted on towers or building roofs provide an alternative to airborne and satellite platforms (Voogt and Oke, 2003). Ground-based TIR remote sensing approaches were part of several studies addressing the energy exchange in urban areas. For instance, Hoyano et al. (1999) used time-sequential thermography (TST) for calculating sensible heat flux density at the building scale. In Tokyo, a TIR camera measured urban surface temperatures from the top of a high-rise building for derivation of a local-scale thermal property parameter (Sugawara et al., 2001). Further ground-based studies used TST for the assessment of thermal characteristics of various urban surfaces (Chudnovsky et al., 2004), to study spatio-temporal differences between surface and air temperature as an important boundary condition for ventilation of the urban canopy layer by buoyancy effects (Yang and Li, 2009), or to study spatiotemporal persistence of shadow effects and surface thermal admittance (Meier et al., 2010).

However, radiative processes in the atmosphere between surface and sensor have an impact on remote sensing data. In the TIR part of the electromagnetic spectrum, atmospheric effects that alter the radiance observed by the sensor include absorption and emission primarily induced by water vapour, carbon dioxide and ozone. These atmospheric effects can lead to temperature differences between true surface temperature and remotely sensed values recorded by the sensor larger than $10 \mathrm{~K}$ (Jacob et al., 2003).

Published by Copernicus Publications on behalf of the European Geosciences Union. 
Several methods are available to remove these atmospheric effects depending on sensor characteristics e.g. the split window technique for multi-channel sensors (Price, 1984; Becker and Li, 1990; Sobrino et al., 1991; Kerr et al., 1992) or the use of radiative transfer models coupled with atmospheric profile data on pressure, temperature and humidity adequate for multi and single-channel sensors (Berk et al., 1998; Schmugge et al., 1998; Richter and Schläpfer, 2002). While these methods are common for data derived from satellite (Prata et al., 1995; Dash et al., 2002) or airborne platforms (Jacob et al., 2003; Lagouarde et al., 2004; Lagouarde and Irvine, 2008), the need for atmospheric correction of ground-based TIR imagery acquired in oblique view is an open question insofar as the 3-D urban form is concerned.

There are only few studies on ground-based measurements, which take atmospheric effects into account. They include either the use of a radiative transfer model to determine a linear relation between observed and corrected surface temperature for target-sensor distances of selected region of interests (Sugawara et al., 2001) or the assumption of a global sensor-target distance and atmospheric transmission value (Yang and $\mathrm{Li}, 2009$ ).

The objective of this paper is to present a comprehensive atmospheric correction procedure for ground-based singlechannel TIR sensors that works on a pixel-by-pixel basis considering the 3-D form of the urban environment and resulting differences in line-of-sight (LOS) geometry due to an oblique viewing geometry.

We give answers on how to derive view zenith angle $\left(\theta_{j}\right)$, surface height a.s.l. $\left(z_{j}^{\text {surf }}\right)$ and sensor-target distances for every image pixel $j$. Further we quantify the magnitude of atmospheric effects on the TST data in the study area during a diurnal cycle using the atmospheric radiative transfer model MODTRAN $^{\mathrm{TM}} 5.2$ (MOD5) (Berk et al., 2005) coupled with profile data from temperature and humidity measurements in the field of view (FOV) of the TIR camera.

Section 2 describes the theoretical background and shows possible atmospheric effects on off-nadir TIR remote sensing in urban areas with the help of a fictitious experimental setup and MOD5 simulations. In Sect. 3 we describe the study site, our experimental setup, pre-processing steps of TIR imagery, LOS parameter determination and the atmospheric correction procedure. Section 4 presents the spatial distribution of LOS parameters and atmospherically corrected TIR imagery during a diurnal cycle. In addition, we compare the results from the spatially distributed atmospheric correction procedure referred to as MLOS (multi line-of-sight) method with a simple approach using non-spatially distributed LOS parameters referred to as SLOS (single line-of-sight) method. Finally, we compare the originally TIR data and the results from the MLOS and SLOS approach with in-situ measurements acquired at one roof in the FOV.

\section{Atmospheric effects on oblique TIR imagery in urban areas}

This section describes the theoretical background of atmospheric effects on long-wave radiation and demonstrates these atmospheric effects with the help of a fictitious urban setup and radiative transfer simulations using MOD5.

\subsection{Theoretical background}

The radiance $L_{i}^{\text {cam }}\left(\theta_{j}, z_{j}^{\text {surf }}\right)$ recorded in channel $i$ of a TIR camera located at a certain height a.s.l. $\left(z^{\mathrm{cam}}\right)$ that observes a surface (image pixel $j$ ) having a certain height a.s.l. $\left(z_{j}^{\text {surf }}\right)$ and under a view zenith angle $\left(\theta_{j}\right)$, is the sum of the surface emission that is attenuated by the atmosphere, the upward radiance emitted by the atmosphere and the radiance from the environment for instance the sky or building walls that is reflected by the ground surface. Under the assumption that the surface is a Lambertian surface, we can write (cf. Sobrino, 1991):

$$
\begin{aligned}
& L_{i}^{\mathrm{cam}}\left(\theta_{j}, z_{j}^{\text {surf }}\right)=\int \mathrm{d} \lambda f_{i}(\lambda) \varepsilon_{\lambda} B_{\lambda}(T) \tau_{\lambda}\left(\theta_{j}, z_{j}^{\text {surf }}, z^{\text {cam }}\right) \\
& \quad+\int \mathrm{d} \lambda f_{i}(\lambda) L_{\lambda}^{\text {atm }}\left(\theta_{j}, z_{j}^{\text {surf }}, z^{\text {cam }}\right) \\
& \quad+\int \mathrm{d} \lambda f_{i}(\lambda) \frac{\left(1-\varepsilon_{\lambda}\right)}{\pi} \tau_{\lambda}\left(\theta_{j}, z_{j}^{\text {surf }}, z^{\text {cam }}\right) L_{\lambda}^{\text {envi }}
\end{aligned}
$$

where $f_{i}(\lambda)$ is the normalized spectral response of the TIR camera in channel $i, \varepsilon_{\lambda}$ is the surface spectral emissivity, $B_{\lambda}$ is the spectral radiance from a blackbody at surface temperature $T, \tau_{\lambda}$ is the spectral transmission of the atmosphere, and $z^{\text {cam }}$ is the altitude of the TIR camera. The term $L_{\lambda}^{\text {atm }}$ in Eq. (1) is the upward atmospheric spectral radiance and is given by

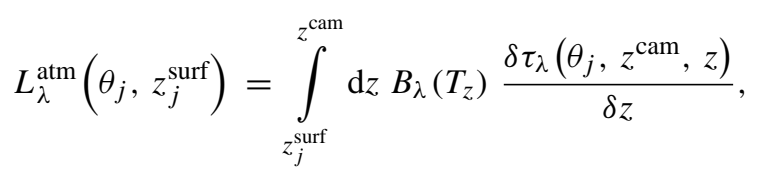

where $\tau_{\lambda}\left(\theta_{j}, z^{\text {cam }}, z\right)$ represents the spectral atmospheric transmittance between the altitude of the TIR camera $z^{\text {cam }}$ e.g. on top of a high-rise building, and the altitude $z$ that depends on how many atmospheric layers we consider in the radiative transfer model. If we consider only one atmospheric layer then $z$ equals the height of the examined urban surface $\left(z=z_{j}^{\text {surf }}\right)$ for instance the wall of the first floor that belongs to another high-rise building. The term $T_{z}$ represents atmospheric temperature at level $z$.

$L_{\lambda}^{\text {envi }}$ in Eq. (1) is the hemispherical value of the downward radiance originated from the environment (e.g. sky, building walls). In this study, the surface emissivity was assumed to unity and therefore we consider a surface brightness temperature $\left(T_{\mathrm{b}}\right)$. This assumption is motivated by the unknown spectral emissivity of the observed urban surfaces. The error caused by the assumption $\varepsilon_{\lambda}=1$ is addressed in Sect. 4 . 

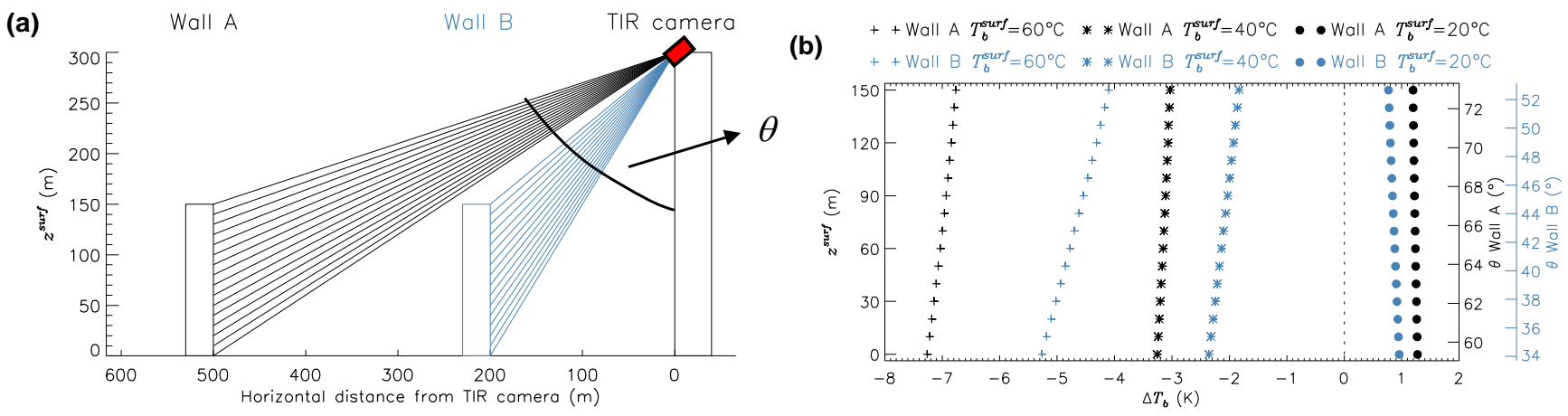

Fig. 1. (a) Scheme of the fictitious experimental setup and line-of-sight (LOS) geometry in order to demonstrate atmospheric effects on oblique TIR imagery in urban areas, (b) vertical profiles of $\Delta T_{\mathrm{b}}$ for wall A (black) and wall B (blue) as a function of wall height ( $z^{\text {surf }}$ ) and corresponding view zenith angle $(\theta)$ for wall temperatures $T_{\mathrm{b}}^{\text {surf }}$ of $20^{\circ} \mathrm{C}, 40^{\circ} \mathrm{C}$ and $60^{\circ} \mathrm{C}$ respectively, uniform air temperature of $25^{\circ} \mathrm{C}$ and relative humidity of $45 \%$.

Therefore, the at-sensor radiance $L_{i}^{\text {cam }}\left(\theta_{j}, z_{j}^{\text {surf }}\right)$ for every pixel $j$ is:

$$
\begin{aligned}
L_{i}^{\text {cam }}\left(\theta_{j}, z_{j}^{\text {surf }}\right) & =\int \mathrm{d} \lambda f_{i}(\lambda) B_{\lambda}\left(T_{\mathrm{b}}\right) \tau_{\lambda}\left(\theta_{j}, z_{j}^{\text {surf }}, z^{\text {cam }}\right) \\
& +\int \mathrm{d} \lambda f_{i}(\lambda) L_{\lambda}^{\text {atm }}\left(\theta_{j}, z_{j}^{\text {surf }}, z^{\text {cam }}\right) .
\end{aligned}
$$

\subsection{Quantification of atmospheric effects using MOD5 and a fictitious urban experimental setup}

The aim of this section is to demonstrate the possible discrepancy $\Delta T_{\mathrm{b}}$ between measured surface brightness temperature $T_{\mathrm{b}}^{\mathrm{cam}}$ by a single-channel TIR sensor and real surface brightness temperature $T_{\mathrm{b}}^{\text {surf }}($ Eq. 4$)$.

$\Delta T_{\mathrm{b}}=T_{\mathrm{b}}^{\mathrm{cam}}-T_{\mathrm{b}}^{\text {surf }}$

For this purpose, we examine a fictitious urban experimental setup as depicted in Fig. 1a. The idea is to evaluate six vertical profiles of $\Delta T_{\mathrm{b}}$ for two building walls $\mathrm{A}$ and $\mathrm{B}$ (both $150 \mathrm{~m}$ high) showing a homogenous $T_{\mathrm{b}}^{\text {surf }}$ of $20^{\circ} \mathrm{C}, 40^{\circ} \mathrm{C}$ and $60^{\circ} \mathrm{C}$ respectively. Wall $\mathrm{A}$ is placed at a horizontal distance of $500 \mathrm{~m}$ from the observer and wall $\mathrm{B}$ at a horizontal distance of $200 \mathrm{~m}$. The camera position $\left(z^{\mathrm{cam}}\right)$ is $300 \mathrm{~m}$ above ground. The spectral characteristics of the singlechannel TIR camera are adopted from our real experimental setup described in Sect. 3. This includes the spectral range $(7.5-14 \mu \mathrm{m})$ and TIR sensor response $f_{i}(\lambda)$ data, which is provided by the camera manufacturer. We calculate vertical profiles of $\Delta T_{\mathrm{b}}$ in the following way.

For given $T_{\mathrm{b}}^{\text {surf }}$, the spectral blackbody radiance is calculated from the Planck equation. This spectral radiance $B_{\lambda}\left(T_{\mathrm{b}}^{\text {surf }}\right)$ is multiplied by the spectral transmission $\tau_{\lambda}\left(\theta, z^{\text {surf }}\right)$ calculated from MOD5 and then added to $L_{\lambda}^{\text {atm }}\left(\theta, z^{\text {surf }}\right)$ calculated from MOD5 for every $\theta$ and corresponding $z^{\text {surf }}$ of the profile points derived from the given LOS geometry. In the next step, we multiply the simulated at-sensor spectral radiance by $f_{i}(\lambda)$ and integrate
( $\mathrm{d} \lambda=20 \mathrm{~nm}$, wavelengths increments of MOD5 runs) to get the band effective radiance $L_{i}^{\mathrm{MOD} 5}$ for the given temperature $T_{\mathrm{b}}^{\text {surf }}$ of the wall. We can write:

$$
\begin{aligned}
L_{i}^{\mathrm{MOD} 5} & =\int_{7.5 \mu \mathrm{m}}^{14.0 \mu \mathrm{m}} \mathrm{d} \lambda\left[B_{\lambda}\left(T_{\mathrm{b}}^{\text {surf }}\right) \tau_{\lambda}\left(\theta, z^{\text {surf }}, z^{\mathrm{cam}}\right)\right. \\
& \left.+L_{\lambda}^{\mathrm{atm}}\left(\theta, z^{\text {surf }}, z^{\mathrm{cam}}\right)\right] f_{i}(\lambda) .
\end{aligned}
$$

The increment of $z^{\text {surf }}$ amounts to $10 \mathrm{~m}$. The atmosphere is considered as only one layer with a uniform air temperature $\left(T_{\text {air }}\right)$ of $25^{\circ} \mathrm{C}$ and a relative humidity (RH) of $45 \%$. Finally, a temperature-radiance look-up table (LUT) can be generated to convert $L_{i}^{\mathrm{MOD} 5}$ into $T_{\mathrm{b}}^{\mathrm{cam}}$. For a range of brightness temperatures $\left(T_{\mathrm{b}}^{\mathrm{LUT}}=T_{\mathrm{b}}^{\text {surf }} \pm 15 \mathrm{~K}\right)$, we use the Plank equation within the sensor wavelengths and weighted by the sensor response $f_{i}(\lambda)$ to produce a band effective radiance for the LUT $\left(L_{i}^{\mathrm{LUT}}\right)$. The simulated $L_{i}^{\mathrm{MOD} 5}$ is then compared to $L_{i}^{\mathrm{LUT}}$ and by an iterative approach using $0.1 \mathrm{~K}$ increments we selected the temperature whose associated integrated radiance in the LUT hat the smallest absolute difference with $L_{i}^{\mathrm{MOD} 5}$.

The vertical profiles of $\Delta T_{\mathrm{b}}$ for wall A (black) and wall B (blue) as a function of LOS geometry and $T_{\mathrm{b}}^{\text {surf }}$ are displayed in Fig. 1b. The results show that $\Delta T_{\mathrm{b}}$ depends on $z^{\text {surf }}, \theta$ and the difference between $T_{\text {air }}$ and $T_{\mathrm{b}}^{\text {surf }}$, which is important for the relationship between atmospheric absorption and atmospheric emission. Cold surfaces $\left(T_{\mathrm{b}}^{\text {surf }}<T_{\text {air }}\right)$ enhance the impact of atmospheric emission, which induced an overestimation of $T_{\mathrm{b}}^{\text {surf }}$. On the other hand, hot surfaces $\left(T_{\mathrm{b}}^{\text {surf }}>T_{\text {air }}\right.$ ) enhance the impact of atmospheric absorption, which induces an underestimation of $T_{\mathrm{b}}^{\text {surf }}$, here by up to more than $7 \mathrm{~K}$. The expanded range of $\theta$ for wall $\mathrm{B}$ leads to a clear vertical gradient of up to $1.2 \mathrm{~K}\left(T_{\mathrm{b}}^{\text {surf }}=60^{\circ} \mathrm{C}\right)$. In the case of wall A the vertical gradient is only between $0.1 \mathrm{~K}$ $\left(T_{\mathrm{b}}^{\text {surf }}=20^{\circ} \mathrm{C}\right)$ and $0.5 \mathrm{~K}\left(T_{\mathrm{b}}^{\text {surf }}=60^{\circ} \mathrm{C}\right)$. In the extreme case 
(a)

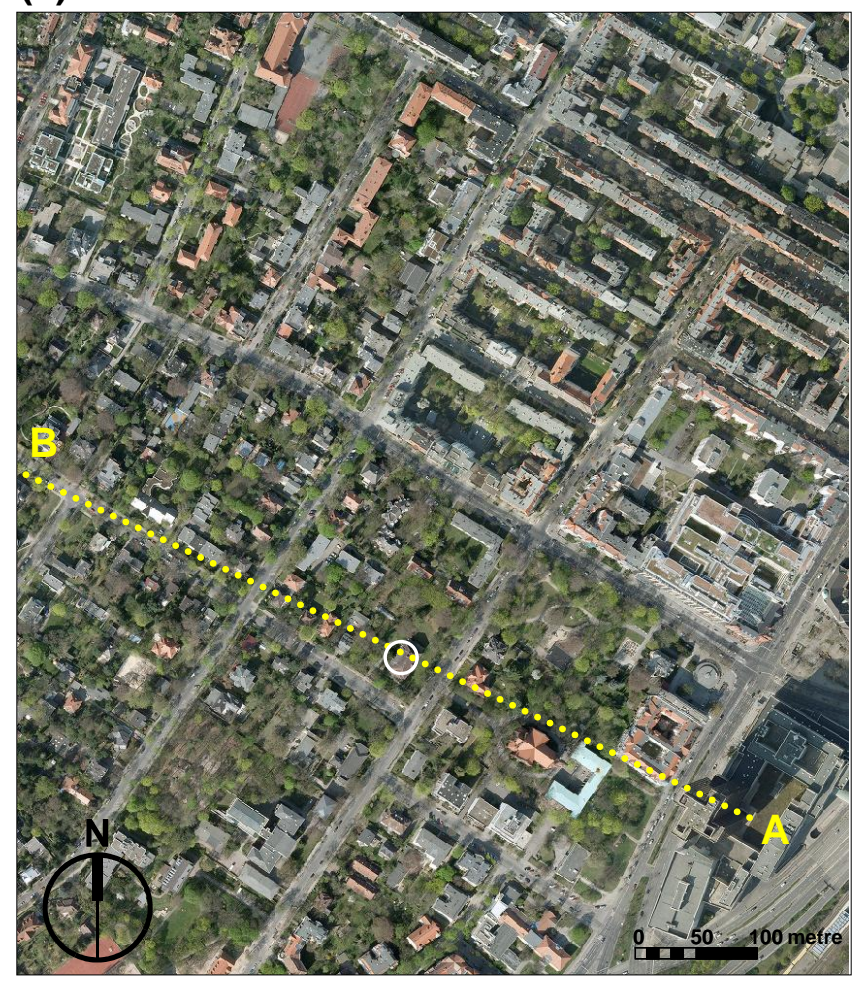

(b)

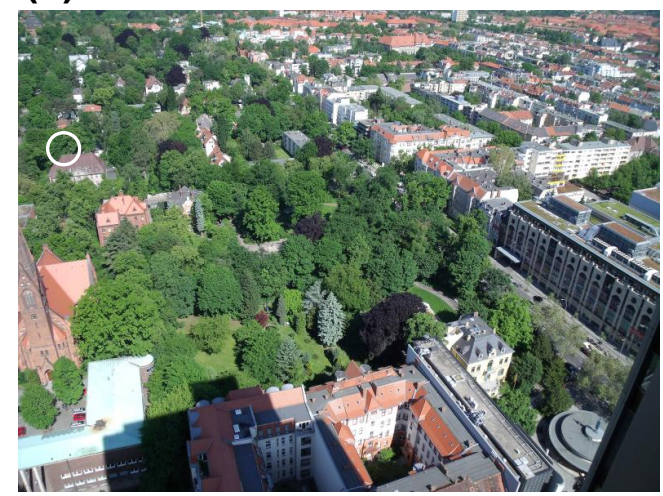

(c)

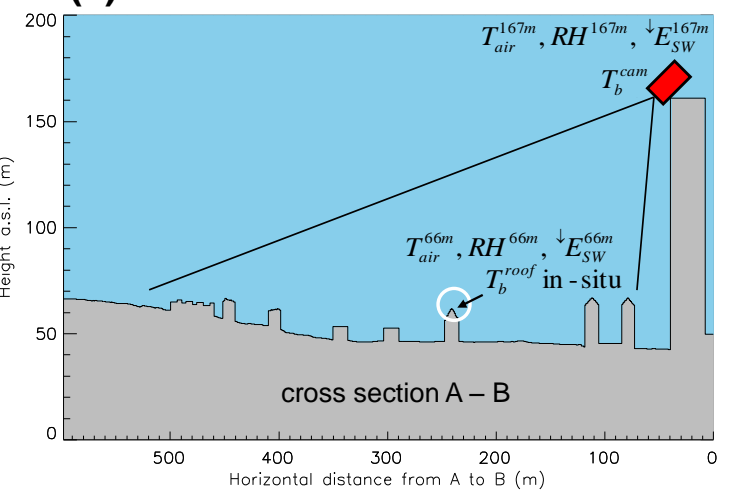

Fig. 2. (a) Aerial photo of the study site and meteorological measurement site (white circle) (aerial photo with permission of Berlin Department of Urban Development, Urban and Environmental Information System), (b) photograph showing approximately the FOV of the TIR camera, (c) cross Sect. A-B illustrates the experimental setup e.g. surface heights, location of TIR camera and in-situ measurements.

$\left(T_{\mathrm{b}}^{\text {surf }}=60^{\circ} \mathrm{C}\right)$, the TIR camera records a temperature difference of up to $3 \mathrm{~K}$ between the bottom of wall $\mathrm{A}$ and the top of wall B in spite of equal wall temperature. The results from this theoretical study emphasise our motivation to develop an atmospheric correction procedure that works on a pixel-bypixel basis considering the 3-D urban form.

\section{Materials and method}

In the following, we describe the experimental setup, data sets used, the calculation of LOS geometry parameters for every pixel of the TIR image and the atmospheric correction procedure.

\subsection{Study site and experimental setup}

The study site is located in Berlin (Germany) in the SteglitzZehlendorf district $\left(52^{\circ} 27^{\prime} \mathrm{N}, 13^{\circ} 19^{\prime} \mathrm{E}\right)$. The site is characterized by a five to six-storey block development, two storey residential houses, parks, trees, villas with gardens and one isolated high-rise building (see also Fig. 2a and b). On the roof of the high-rise building we have installed a TIR camera system (InfraTec VarioCAM head, $320 \times 240$ pixels) in order to record the spatial distribution of upward long-wave radiation continuously. For details on technical specifications of the TIR camera system, please see Meier et al. (2010).

During routine operation, the TIR camera records one image per minute. The fixed camera position during this study ensures a valid comparison between the multi-temporal imagery. The experimental setup is supplemented by meteorological measurements on top of the high-rise building (167 $\mathrm{m}$ a.s.1.), as well as near-ground instrumentation (66 m a.s.l., see also white circle in Fig. 2) within the FOV of the TIR camera in order to provide humidity and air temperature profile input data for MOD5. Measurement frequency is $5 \mathrm{~s}$ for air temperature $\left(T_{\text {air }}^{66 \mathrm{~m}}, T_{\text {air }}^{167 \mathrm{~m}}\right)$, relative humidity $\left(\mathrm{RH}^{66 \mathrm{~m}}, \mathrm{RH}^{167 \mathrm{~m}}\right)$ devices (Vaisala, HMP45A) and downward short-wave radiation $\left({ }^{\downarrow} E_{\mathrm{sw}}^{66 \mathrm{~m}},{ }^{\downarrow} E_{\mathrm{sw}}^{167 \mathrm{~m}}\right)$ devices (Kipp \& Zonen, CM3). Further, we installed one pyrometer measurement device (Heimann, KT15) directly above the roof to obtain in-situ surface brightness temperature $\left(T_{\mathrm{b}}^{\text {roof }}\right)$ for validation of the atmospheric correction procedure (Fig. 2c, white circle). The pyrometer is located $1 \mathrm{~m}$ offset from the roof and observes the roof under the same view zenith angle as the TIR camera. 
(a) Gain

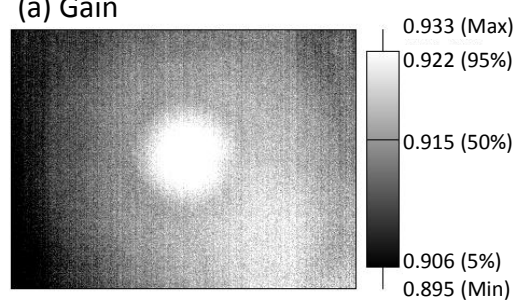

(b) Offset

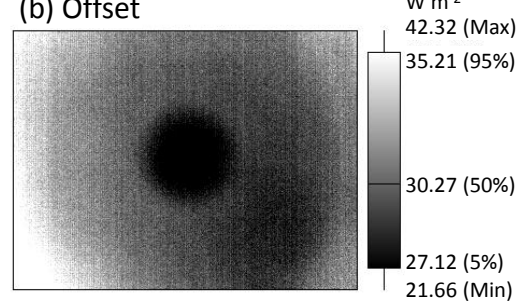

(c) RMSE $\quad \mathrm{W} \mathrm{m}^{-2}$

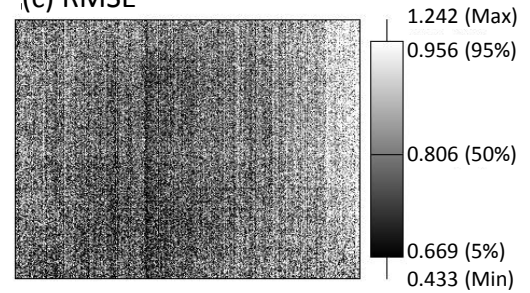

Fig. 3. Radiometric correction parameters for every pixel of the TIR camera system derived from radiometric measurements of a homogenous plate using a reference pyrometer.

\subsection{Pre-processing, radiometric and geometric corrections of TIR imagery}

The TIR camera system provides calibration metadata for each recorded image, derived from firmware calibration using laboratory blackbody temperatures. Depending on case temperature, the system generates calibration metadata in a user-defined frequency. The first step of image processing uses these internal calibration parameters for converting measured radiance (digital numbers, DN) into at-sensor brightness temperature $T_{\mathrm{b}}^{\mathrm{cam}}$ for each pixel. It is possible to convert $T_{\mathrm{b}}^{\mathrm{cam}}$ into at-sensor long-wave radiation flux density $\left(E^{\mathrm{cam}}\right)$ via Stefan-Boltzmann law or into at-sensor radiance $L_{i}^{\text {cam }}$ by using the integral of the Planck equation at the sensors wavelengths and weighted by $f_{i}(\lambda)$ in order to do further corrections of TIR imagery based on radiance values.

\subsubsection{Radiometric correction}

The wide-angle lens itself and the parameters of geometric projection of radiance on a non-spherical sensing element (Mitchell, 2010) can cause vignetting, which refers to the effect of radiance reduction towards the borders of a recorded image relative to its projection centre. The latter effect is often referred to as the "cosine fourth" law (e.g. Sands, 1973). It refers to the process that on a flat sensing element, uniform radiance is not causing uniform radiance as we move off-axis away from the centre of the image.

This effect is probably superimposed by radiance caused by retro-reflections of the detector onto itself (Narcissus effect) in combination with effects of the polyethylene foil and camera enclosure that protects the sensor in the field. Further laboratory measurements with and without foil and enclosure show that they have an influence on the radiance field apart from lens vignetting. For correction of these combined effects we carried out an experiment in a climate chamber at our Institute in which we measured the surface brightness temperature and long-wave radiation (StefanBoltzmann law) of a homogenous plate with a reference pyrometer (Heitronics KT19) in discrete steps of $5 \mathrm{~K}$. The air temperature in the climate chamber was varied between 5$30^{\circ} \mathrm{C}$ and kept constant over $2 \mathrm{~h}$. For every temperature interval we measured the same plate with the TIR camera and calculated the offset and gain values for every pixel in relation to the reference pyrometer. The correction parameters of this linear correction model and the root mean square error (RMSE) are shown in Fig. 3.

\subsubsection{Geometric correction}

The used wide-angle lens produces geometric distortions. These deformations were analysed by measuring a grid of metallic pins in a regular square pattern. We used the positions of the metallic pins to construct a Delaunay triangulation of a planar set of points. Then the geometrical deviations in $\mathrm{x}$ - and y-direction were interpolated for each image pixel. By using a nearest-neighbour technique, the TIR image pixels can be shifted to their real positions. After correction of lens deformation, the TIR image covers a FOV of $57.5^{\circ}$ by $44.7^{\circ}$. Other experiments with TIR cameras using wideangle lenses (e.g. Lagouarde et al., 2004) also reported such effects.

\subsection{Spatially distributed line-of-sight (LOS) geometry determination}

The determination of spatially distributed LOS geometry parameters is based on digital surface model (DSM) data, photogrammetry and 3-D computer vision techniques. The idea is to link the TIR image pixels to corresponding 3-D coordinates via geometrical transformations used in computer graphics (Foley and van Dam, 1984) based on camera interior and exterior orientation parameters.

At first, we merged the 3-D building vector model, which is available for Berlin in the CityGML format (Kolbe, 2009), and the digital ground model (DGM), which is available in $1 \mathrm{~m}$ resolution, into a vector-based DSM. At present, the DSM does not include trees or any other vegetation. Therefore, the atmospheric correction of vegetative TIR pixels uses LOS parameters representing the nearest underlying ground, wall or roof surface.

In order to model the perspective projection of 3-D objects onto the two-dimensional (2-D) TIR image plane, we translate the origin of the DSM coordinate system to the vanishing 
point of the perspective projection using the following equation:

$$
\left(\begin{array}{l}
x \\
y \\
z
\end{array}\right)=\left(\begin{array}{l}
X_{\mathrm{DSM}} \\
Y_{\mathrm{DSM}} \\
Z_{\mathrm{DSM}}
\end{array}\right)-\left(\begin{array}{l}
X_{\mathrm{VP}} \\
Y_{\mathrm{VP}} \\
Z_{\mathrm{VP}}
\end{array}\right)
$$

where $x, y, z$ are the coordinates in the new camera reference system, $X_{\mathrm{DSM}}, Y_{\mathrm{DSM}}, Z_{\mathrm{DSM}}$ are the 3-D coordinates of a point in the originally DSM object space coordinate system and $X_{\mathrm{VP}}, Y_{\mathrm{VP}}, Z_{\mathrm{VP}}$ are the 3 -D coordinates of vanishing point of the perspective projection, which is the fixed TIR camera position.

The next step defines a view volume in order to realise the interior orientation. In our perspective projection, this is a frustum of a pyramid. Objects that fall within the view volume are projected toward the apex of the pyramid (viewpoint or eye position). Objects that are closer to the viewpoint appear larger because they occupy a proportionally larger amount of the view volume than those that are farther away, in the larger part of the frustum. The bounds of the view volume are described by the FOV parameters of the wide-angle lens of the TIR camera after geometric correction.

The exterior orientation was determined by using the optical centre point $\left(P_{\mathrm{o}}\right)$ of the TIR image and its coordinates in the camera reference system $\left(x_{0}, y_{0}, z_{0}\right)$. Then the view zenith angle $\left(\theta_{\mathrm{o}}\right)$ between nadir viewing position and $P_{\mathrm{o}}$ was calculated (Eq. 9) to execute the first rotation of the DSM around the horizontal $\mathrm{x}$-axis (West-East) of the camera reference system using $\theta_{\mathrm{o}}$ and 3-D rotation matrix calculation (Foley and van Dam, 1984).

$\tan \left(\theta_{\mathrm{o}}\right)=\frac{\sqrt{x_{\mathrm{o}}^{2}+y_{\mathrm{o}}^{2}}}{\left|z_{\mathrm{o}}\right|}$

The view azimuth angle $\left(\varphi_{\mathrm{o}}\right)$ between the horizontal y-axis (North-South) and $P_{\mathrm{o}}$ was calculated (Eq. 10) to execute the second rotation of the DSM around the vertical z-axis of the camera reference system.

$\tan \left(\varphi_{\mathrm{o}}\right)=\frac{x_{\mathrm{o}}}{y_{\mathrm{o}}}$

The TIR camera was installed horizontally and allows no tilt around the horizontal y-axis. Hence, a third rotation around this $y$-axis is not necessary to navigate the DSM in the correct perspective of the TIR camera.

Further, we selected 12 ground control points (GCP) from the DSM data set in order to calculate the RMSE between LOS geometry values derived directly from $x, y, z$ coordinates of GCP and corresponding pixel values of LOS geometry patterns.

\subsection{Atmospheric correction procedure}

The flowchart of the MLOS atmospheric correction procedure is illustrated in Fig. 4. We applied the workflow to 30min averages of TIR and meteorological data. In order to analyse TST data representing a diurnal cycle, we processed 48 TIR images.

The integrated at-sensor radiance $\left(L_{i}^{\mathrm{MOD} 5}\right)$ was simulated for a range of surface brightness temperatures based on air temperature $\left(T_{\mathrm{b}}^{\mathrm{MOD} 5} \in\left[T_{\text {air }}^{66 \mathrm{~m}}-5 \mathrm{~K}, T_{\text {air }}^{66 \mathrm{~m}}+45 \mathrm{~K}\right]\right)$ with a $1 \mathrm{~K}$ step and a range of LOS parameters with a $5^{\circ}$ step size for $\theta$ and a $10 \mathrm{~m}$ step size for $z^{\text {surf }}$ respectively. These input parameters show a reasonable temperature and LOS resolution and that takes into account the lower and upper limits of each parameter. The MOD5 atmospheric profile was divided into three levels between $z^{\text {surf }}$ and $z^{\text {cam }}$. Therefore, we used linear interpolated atmospheric profile data $T_{\text {air }}(z)$ and $\mathrm{RH}(z)$ derived from the meteorological measurements. Up to now, we only used TIR data from clear-sky days and hence we did not use the cloud options of MOD5. Overall, 2750 MOD5 runs were used to build-up a LUT for every 30-minute interval.

Since we know the LOS parameters $\left(\theta_{j}, z_{j}^{\text {surf }}\right)$ for every pixel $j$, it is possible to obtain bilinear interpolated LUT values $\left(L_{i}^{\text {MOD5_bilin }}\right)$ on a pixel-by-pixel basis relating the 50 input values of $T_{\mathrm{b}}^{\mathrm{MOD} 5}$ to the simulated at-sensor radiances. Further, $T_{\mathrm{b}}^{\mathrm{cam}}$ is converted into $L_{i}^{\mathrm{cam}}$ by using the integral of the Planck equation at the sensors wavelengths and weighted by $f_{i}(\lambda)$ to relate the measured at-sensor brightness temperature to simulated at-sensor radiance. Finally atmospherically corrected surface brightness temperature $T_{\mathrm{b}}^{\text {surf }}$ is obtained by linear interpolation using $L_{i}^{\text {cam }}, L_{i}^{\text {MOD5_bilin }}$ and $T_{\mathrm{b}}^{\mathrm{MOD} 5}$ (see also Fig. 4).

The SLOS atmospheric correction method is similar to the method described above, but only one LOS parameter pair is used that represents the median of all $\theta_{j}$ and the median of all $z_{j}^{\text {surf }}$. Please note, this simple LOS description is already a result of navigating the DSM into the 2-D TIR image projection and cannot be equated with $\theta_{\mathrm{o}}$ and $\varphi_{\mathrm{o}}$. The SLOS method only needs 50 MOD5 simulations in order to make an atmospheric correction of one image.

\section{Results and discussion}

This section presents the spatial distribution of LOS parameters and atmospherically corrected TIR imagery during a diurnal cycle and the 24-hourly average. Further, we show the difference between $T_{b}^{c a m}$ and the atmospheric corrections from MLOS $\left(T_{\mathrm{b}}^{\mathrm{MLOS}}\right)$ and SLOS $\left(T_{\mathrm{b}}^{\mathrm{SLOS}}\right)$ method and discuss the results from MLOS and SLOS atmospheric correction procedures in relation to in-situ surface brightness temperature $\left(T_{\mathrm{b}}^{\text {roof }}\right)$ and the magnitude of atmospheric effects in relation to sealed and non-sealed surfaces.

\subsection{Line-of-sight (LOS) geometry}

In the visualizations (Fig. 5), we scaled the values of LOS geometry between $95 \%$ percentile (maximum brightness) and $5 \%$ percentile (minimum brightness). Furthermore, 


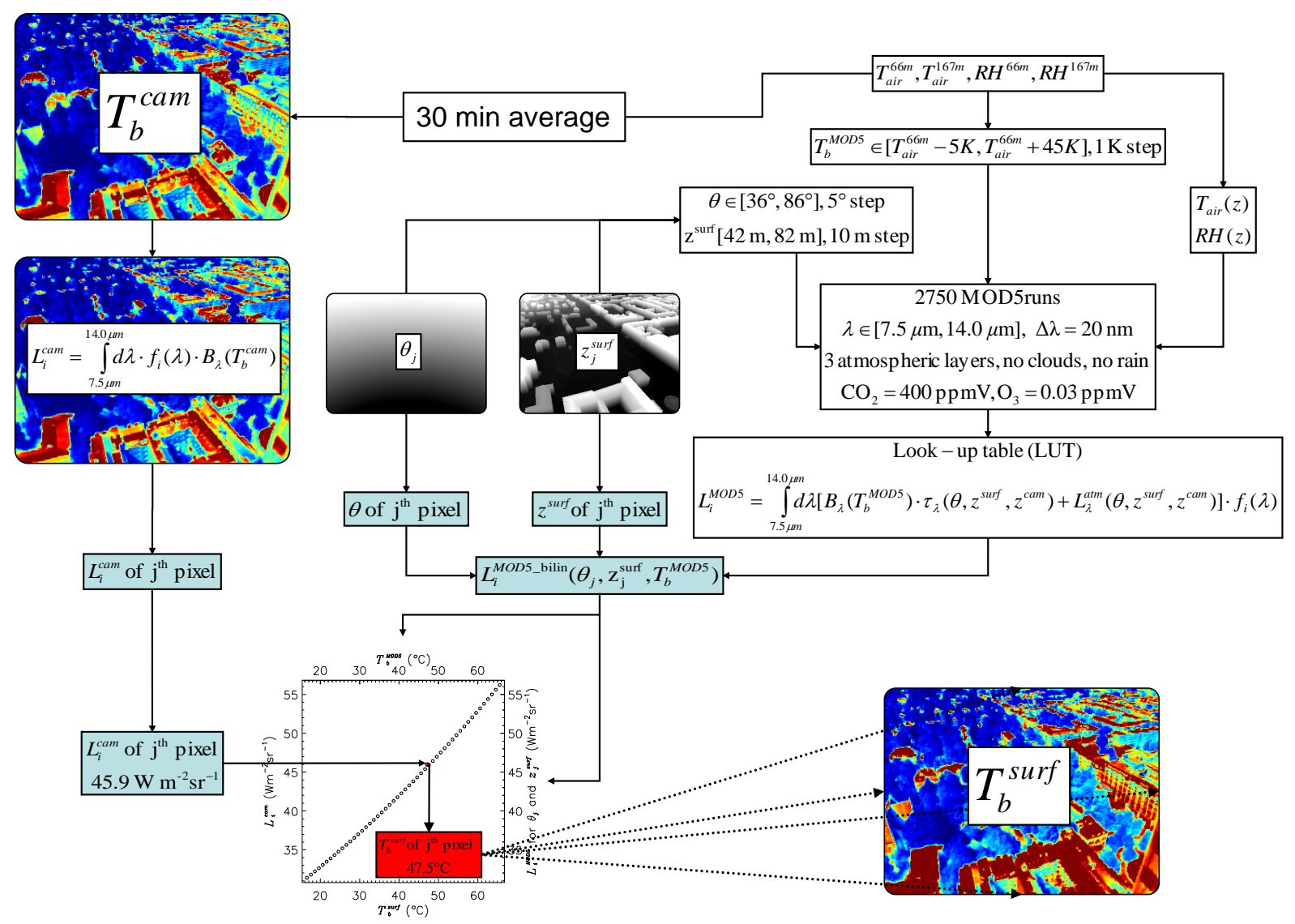

Fig. 4. Flowchart of the multi line-of-sight (MLOS) method on a pixel-by-pixel basis for correction of atmospheric effects in off-nadir TIR imagery acquired in an urban environment.

(a) Visualisation of DSM

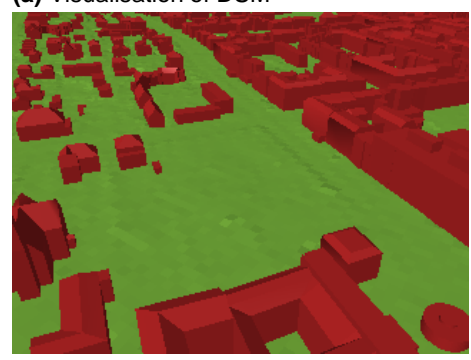

(c) Surface height $\left(z_{i}^{\text {surf }}\right)$ a.s.l.

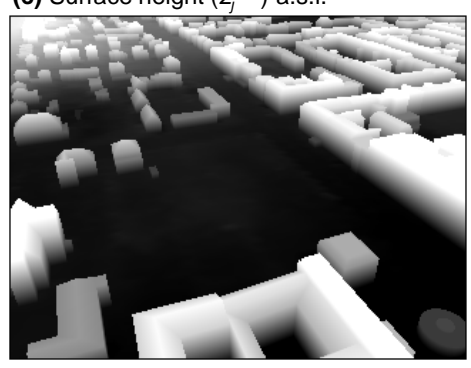

(b) View zenith angle $\left(\theta_{j}\right)$
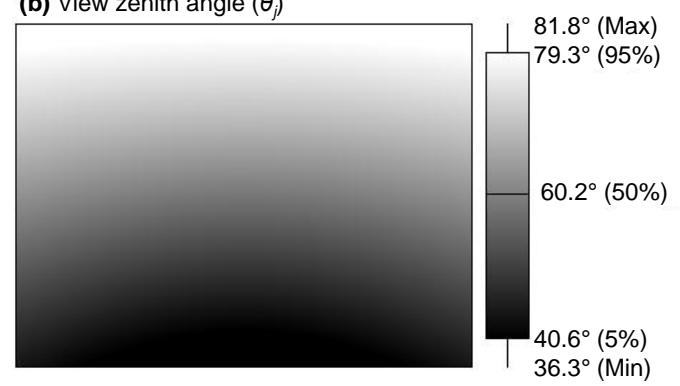

(d) Atmospheric path length
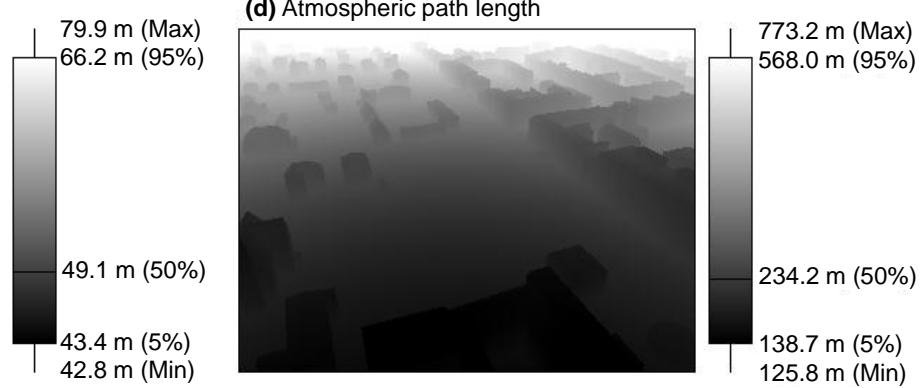

Fig. 5. (a) Perspective projection of the DSM, spatial distribution of LOS geometry parameters: (b) view zenith angle $\theta_{j}$, (c) surface height $z_{j}^{\text {surf }}$ and (d) atmospheric path length. 


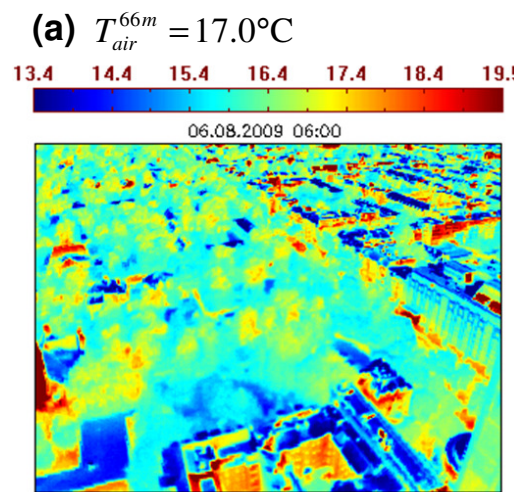

(d) $T_{\text {air }}^{66 m}=21.1^{\circ} \mathrm{C}$

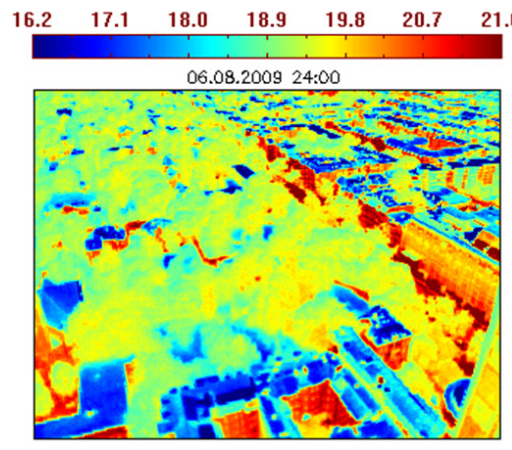

(b) $T_{\text {air }}^{66 \mathrm{~m}}=21.0^{\circ} \mathrm{C}$

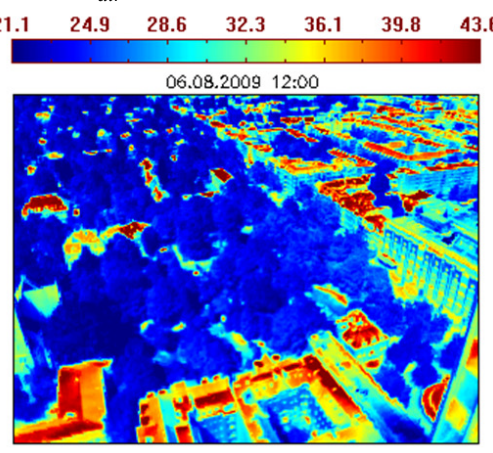

(e) $T_{\text {air }}^{66 m}=21.2^{\circ} \mathrm{C}$

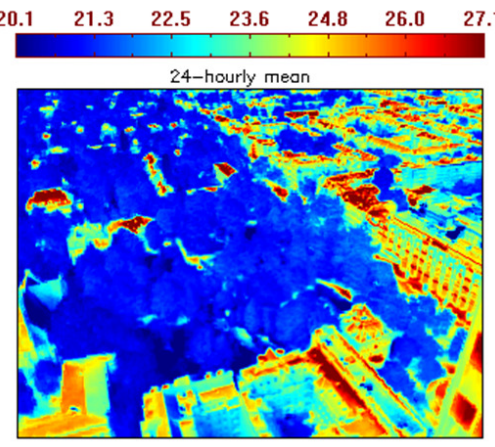

(c) $T_{\text {air }}^{66 m}=26.1^{\circ} \mathrm{C}$

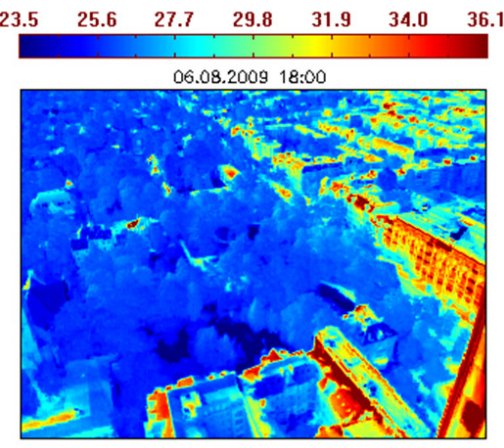

(f)

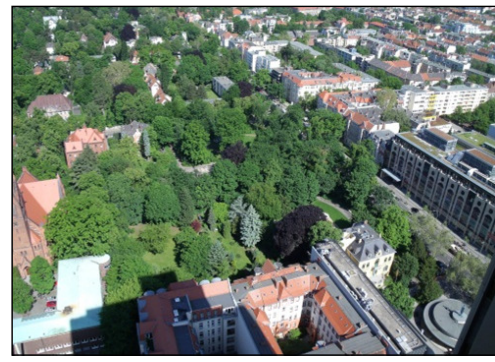

Fig. 6. Atmospherically corrected TIR imagery using the MLOS method for selected 30-min periods during 6 August 2009 at (a) 06:00, (b) 12:00, (c) 18:00 and (d) 24:00 CET, (e) the 24-hourly mean pattern and (f) a photograph showing the FOV of TIR camera.

all grey-scale bars have benchmarks for minimum, median $(50 \%)$ and maximum value. The same visualisation approach is used for TIR imagery presented in Fig. 6.

The perspective projection of the 3-D DSM is visualized in Fig. 5a. Please note, a wall of the high-rise building carrying the TIR camera is not visible in Fig. 5a, but in the TIR image, we can see this wall in the lower right corner (Fig. 6). This polygon object of the DSM is not visualized, because it is too close to the viewpoint and it lies not fully in the view volume. Thus, the LOS parameters for this wall surface are biased. This surface is excluded from our further analysis.

Figure $5 \mathrm{~b}$ shows the spatial distribution of $\theta_{j}$. The range amounts to $45.5^{\circ}$ and is 2.5 times higher than in our fictitious experimental setup (Sect. 2). For the SLOS method, we used the median $\theta_{j}$ that amounts to $60.15^{\circ}$. The RMSE between view zenith angles $\theta_{\mathrm{GCP}}$ derived from 3-D coordinates of the $12 \mathrm{GCP}$ and the corresponding values in the LOS pattern amounts to $0.8^{\circ}$. Figure $5 \mathrm{c}$ shows the spatial distribution of $z_{j}^{\text {surf }}$. The range amounts to $37.1 \mathrm{~m}$, which is approximately $25 \%$ of the range in comparison to the fictitious experimental setup. The highest surfaces are the roofs of the five-storey buildings, the church and the roofs in the background located on a small hill. For the SLOS method, we used the median $z_{j}^{\text {surf }}$ that amounts to $49.1 \mathrm{~m}$. The RMSE for $z_{j}^{\text {surf }}$ is $1.1 \mathrm{~m}$. Overall, the atmospheric path length on the
FOV varies between $125.8 \mathrm{~m}$ and $773.2 \mathrm{~m}$ and the RMSE is $2.9 \mathrm{~m}$ (Fig. 5d).

\subsection{Diurnal cycle of multi line-of-sight (MLOS) atmospherically corrected TIR imagery}

We present atmospherically corrected TST data from $6 \mathrm{Au}-$ gust 2009 at 06:00 (Fig. 6a), 12:00 (Fig. 6b), 18:00 (Fig. 6c) and 24:00 (Fig. 6d). All time specifications refer to CET and the end of the 30-min averaging period. The 24-hourly mean pattern is presented in Fig. 6e and to facilitate interpretability a corresponding photograph of the study site is added (Fig. 6f).

During this day, clear sky conditions caused high downward short-wave irradiance with a maximum of $800 \mathrm{~W} \mathrm{~m}^{-2}$ around noon. The daily mean $T_{\text {air }}^{66 \mathrm{~m}}$ was $21.2^{\circ} \mathrm{C}$, the maximum value was $26.1^{\circ} \mathrm{C}$ at 17:00 and the minimum value was $16.5^{\circ} \mathrm{C}$ at 05:00. During daytime, trees and shadowed surfaces have the lowest temperatures. In contrast, roofs, sunlit walls and street surfaces show the highest temperatures, for instance several roofs reaching more than $40^{\circ} \mathrm{C}$ at $12: 00$ (Fig. 6b red coloured surfaces). The roofs and lawns show the lowest values at night in the thermal pattern and the walls and sealed surfaces show the highest values. The trees are in the medium range showing slightly higher temperatures than 
(a)

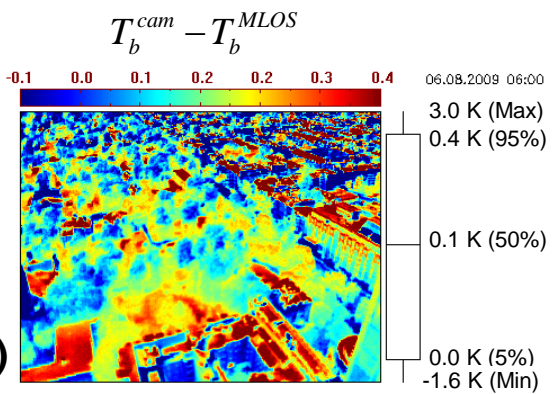

(b)

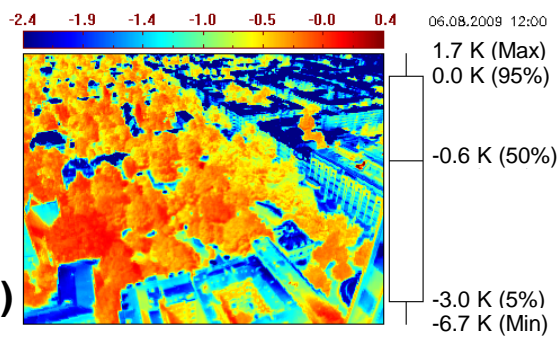

(c)

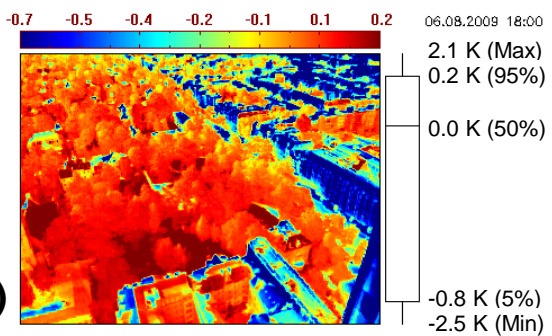

(d)

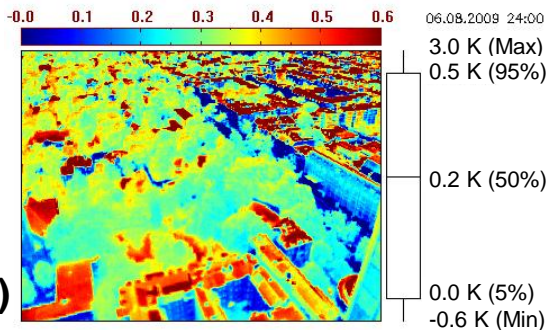

(e)

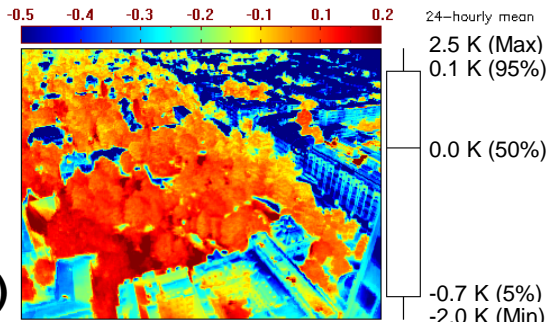

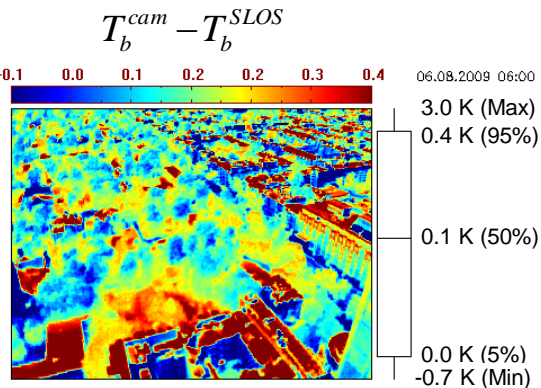
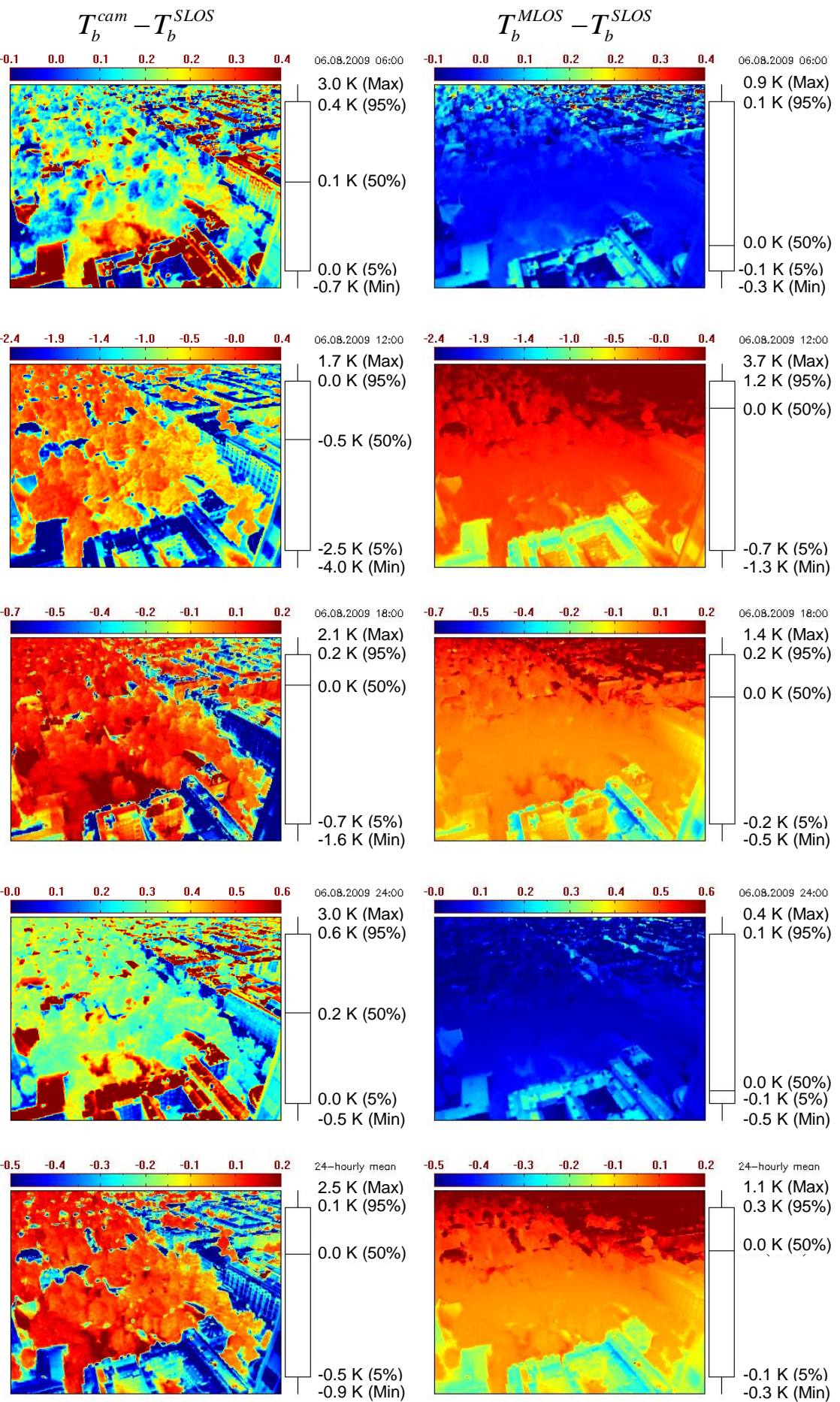

Fig. 7. Differences between $T_{\mathrm{b}}^{\mathrm{cam}}$ and $T_{\mathrm{b}}^{\mathrm{MLOS}}$ (left column), $T_{\mathrm{b}}^{\mathrm{cam}}$ and $T_{\mathrm{b}}^{\mathrm{SLOS}}$ (middle column) and between the two atmospheric correction methods $\left(T_{\mathrm{b}}^{\mathrm{MLOS}}-T_{\mathrm{b}}^{\mathrm{SLOS}}\right.$, right column) for selected 30-minute periods during 6 August 2009 at (a) 06:00, (b) 12:00, (c) 18:00 and (d) 24:00 CET and (e) the 24-hourly mean pattern. 
(a)

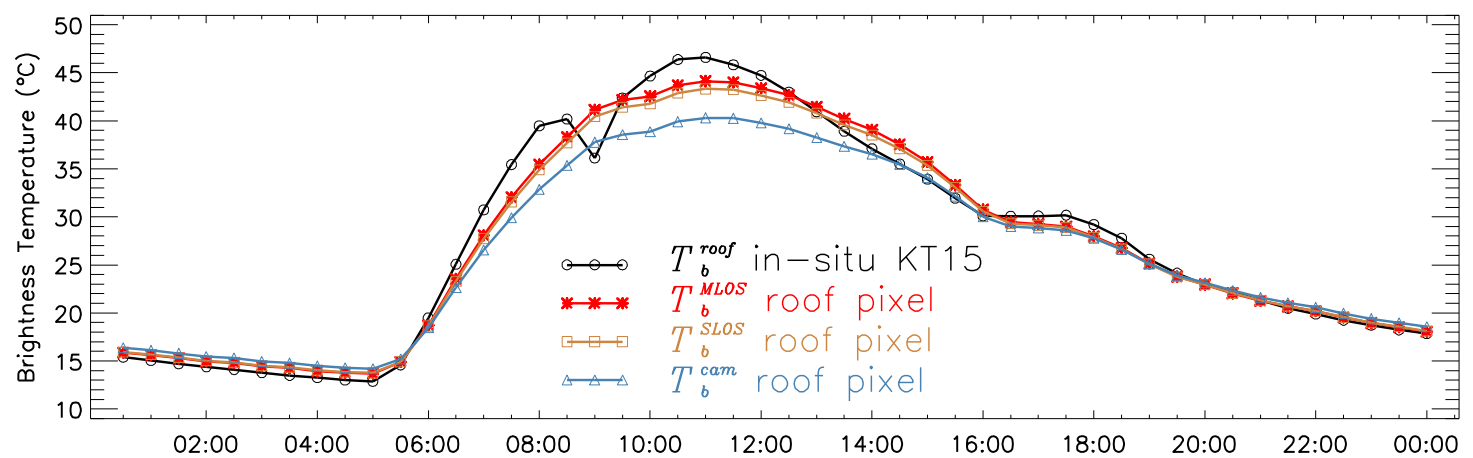

(b)

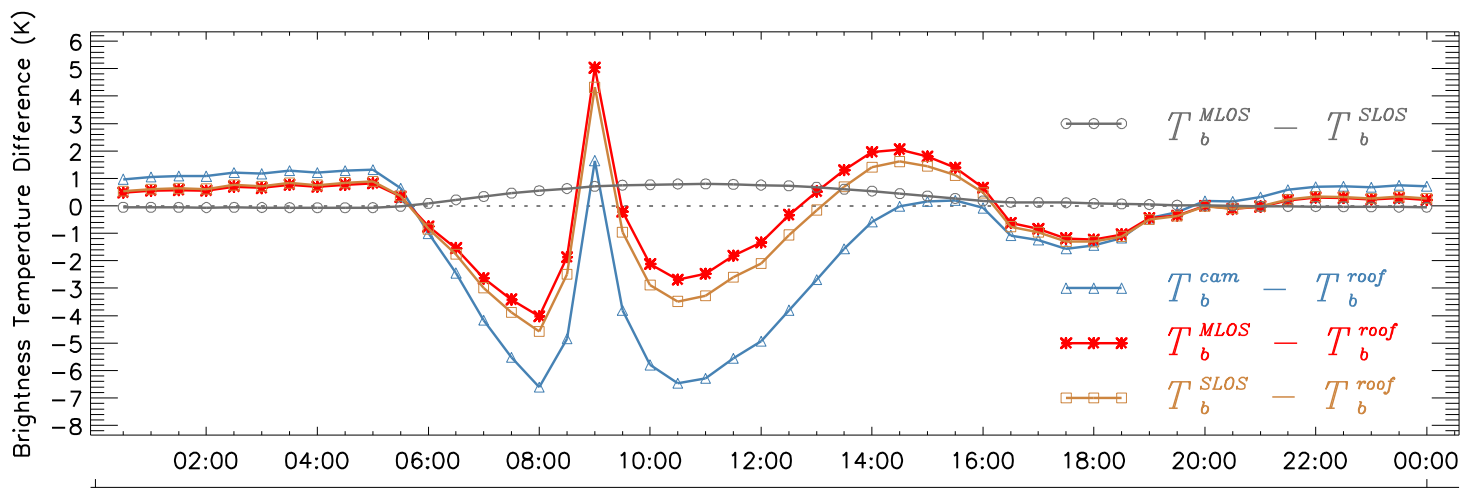

06 Aug, 2009

07 Aug, 2009

Fig. 8. (a) Diurnal variation of $T_{\mathrm{b}}^{\text {roof }}$ and corresponding TIR remote sensing data ( $\left.T_{\mathrm{b}}^{\mathrm{cam}}, T_{\mathrm{b}}^{\mathrm{MLOS}}, T_{\mathrm{b}}^{\mathrm{SLOS}}\right)$ and (b) variation of difference between $T_{\mathrm{b}}^{\text {roof }}$ and corresponding TIR remote sensing data and difference between $T_{\mathrm{b}}^{\mathrm{MLOS}}$ and $T_{\mathrm{b}}^{\text {SLOS }}$ during 6 August 2009.

roof surfaces. In the 24-hourly mean pattern the order from low to high temperatures is as follows: shadowed lawn, trees, building walls, sealed surfaces and roofs (Fig. 6e).

\subsection{Multi line-of-sight (MLOS) versus single line-of-sight (SLOS) approach}

A visualization approach using fixed colour bars allows interpretation of differences in TIR patterns. Therefore, the values for image scaling (Fig. 7) are derived from all three TIR images showing the difference between $T_{\mathrm{b}}^{\mathrm{cam}}$ and $T_{\mathrm{b}}^{\mathrm{MLOS}}$ (left column), the difference between $T_{\mathrm{b}}^{\mathrm{cam}}$ and $T_{\mathrm{b}}^{\mathrm{SLOS}}$ (middle column) and the difference between the two atmospheric correction methods $\left(T_{\mathrm{b}}^{\mathrm{MLOS}}-T_{\mathrm{b}}^{\mathrm{SLOS}}\right.$, right column), representing the same 30-min periods as in Fig. 6 . The box on the right side of every image plot shows the range of individual image values in order to allow quantitative comparison.

During daytime (Fig. $7 \mathrm{~b}$ and c), the MLOS atmospheric correction reveals that at-sensor values are consistently lower than $T_{\mathrm{b}}^{\mathrm{MLOS}}$. There is a clear spatial gradient showing a greater difference for surfaces located further away from the TIR camera. This is particularly noticeable for very hot surfaces. For instance, underestimation of roof surfaces in the background reaches up to $6.7 \mathrm{~K}$ at 12:00. The SLOS method also reveals a similar at-sensor underestimation depending on surface temperature (up to $4 \mathrm{~K}$ at 12:00) but a spatial gradient is not visible. The comparison of both atmospheric correction methods (Fig. $7 \mathrm{~b}$, right column) shows a clear spatial gradient where the MLOS values are higher (up to $3.7 \mathrm{~K}$ ) in the background and lower in the foreground (up to $-1.3 \mathrm{~K}$ ).

During night-time and immediately after sunrise, atmospheric effects are lower than during daytime. The difference between $T_{\mathrm{b}}^{\mathrm{cam}}$ and the two atmospheric correction methods at 24:00 only varies between $-0.6 \mathrm{~K}$ and $3 \mathrm{~K}$. The TIR camera overestimates cold surfaces $\left(T_{\mathrm{b}}^{\text {surf }}<T_{\text {air }}\right)$ e.g. for roofs furthest away from sensor and underestimates hot surfaces $\left(T_{\mathrm{b}}^{\text {surf }}>T_{\text {air }}\right)$ in the case of roads and walls whereas the MLOS pattern (Fig. 7d, left column) reveals the clear dependency on atmospheric path length. This spatial gradient is not visible in the SLOS pattern (Fig. 7d, middle column). However, the differences between MLOS and SLOS are very low e.g. less than $0.5 \mathrm{~K}$ (Fig. $7 \mathrm{~d}$, right column). The 24-hourly patterns are similar to the daytime patterns but with an overall lower magnitude.

\subsection{In-situ data comparison}

The comparison between $T_{\mathrm{b}}^{\text {roof }}$ and the corresponding remote sensing data (roof pixel) shows that in-situ temperatures are consistently higher than $T_{\mathrm{b}}^{\mathrm{cam}}$ with the exception of a short period in the morning between 08:30 and 09:30 (Fig. 8a). 

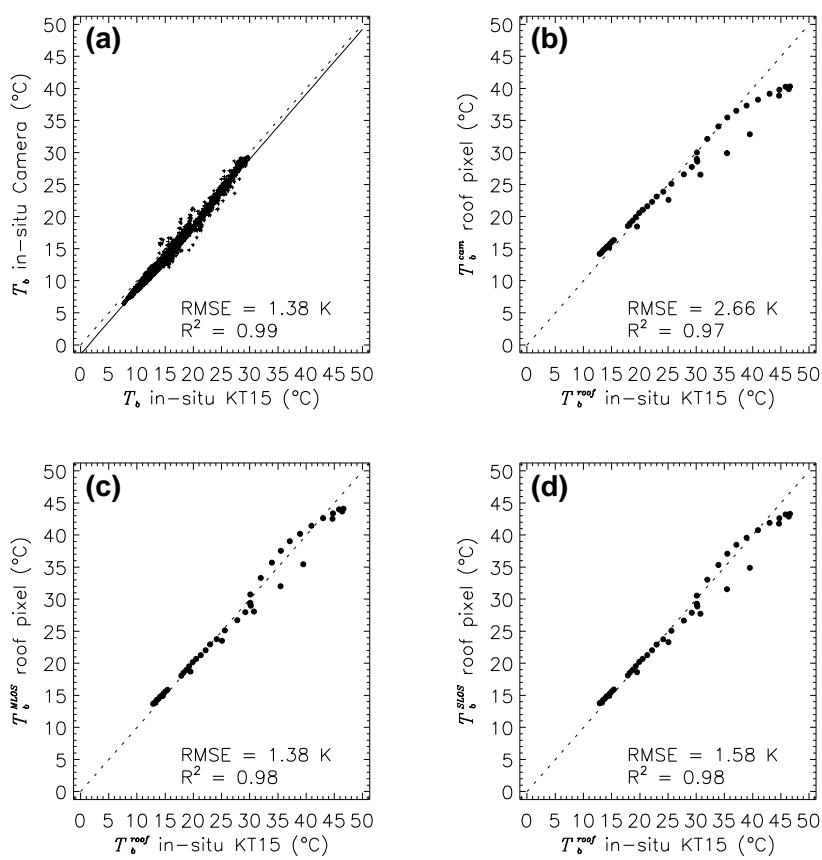

Fig. 9. (a) Instrument comparison over 10 days in April 2010 and relation between $T_{\mathrm{b}}^{\text {roof }}$ in-situ and the corresponding remote sensing data (b) $T_{\mathrm{b}}^{\mathrm{cam}}$, (c) $T_{\mathrm{b}}^{\mathrm{MLOS}}$ and (d) $T_{\mathrm{b}}^{\mathrm{SLOS}}$.

During this time, the installation mast produces a shadow at the target surface of the KT15 pyrometer. This short-term decrease in the morning was also measured at other clear-sky days. The values between 08:30 and 09:30 are excluded from the correlation and RMSE analysis (Fig. 9b-d). The difference between $T_{\mathrm{b}}^{\text {roof }}$ and $T_{\mathrm{b}}^{\mathrm{cam}}$ is clearly reduced due to atmospheric correction, whereas the MLOS method produces a RMSE of $1.4 \mathrm{~K}$ and the SLOS method a RSME of $1.6 \mathrm{~K}$ (Fig. 9c and d). The deviation of the roof LOS geometry parameters $\left(\theta_{j}=70.1^{\circ}, z_{j}^{\text {surf }}=60.5 \mathrm{~m}\right)$ from the SLOS input parameters used for MOD5 simulations caused the difference between MLOS and SLOS with a maximum of 0.8 K at 11:00 (Fig. 8b).

Overall the comparison to in-situ data is critical, because the examined roof is not a strictly homogenous surface. The uneven roof tiles cause small shadow patterns. This is important for the small FOV $\left(9^{\circ}\right)$ of the in-situ KT15 if a great portion of the target is shadowed. The device is installed very close $(1 \mathrm{~m})$ to the pitched roof resulting in a target area of $0.03 \mathrm{~m}^{2}$. The geometric resolution of a roof pixel amounts to $1.1 \mathrm{~m}$ due to the distance of $310 \mathrm{~m}$ between roof and TIR camera. Thus, the FOV of the in-situ measurements covers only $3 \%$ of the TIR camera pixel.

In April 2010, we have conducted an instrument comparison experiment in the garden of our Institute over 10 days in order to estimate the absolute difference between the TIR camera and in-situ pyrometer without atmospheric effects. The results from this measurement show that the KT15
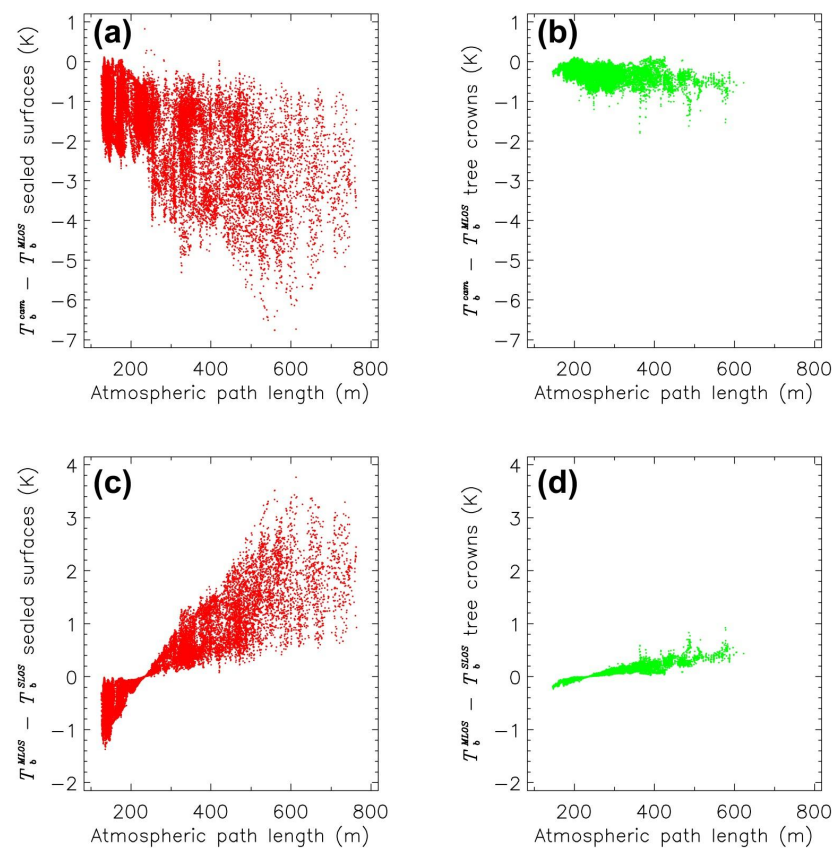

Fig. 10. Relation between atmospheric path length and $T_{\mathrm{b}}^{\mathrm{cam}}-$ $T_{\mathrm{b}}^{\mathrm{MLOS}}$ at 12:00 for (a) sealed surfaces and (b) tree crowns. Relation between atmospheric path length and $T_{\mathrm{b}}^{\mathrm{MLOS}}-T_{\mathrm{b}}^{\text {SLOS }}$ at 12:00 for (c) sealed surfaces and (d) tree crowns.

device in comparison to the TIR camera produces consistently higher values. The RMSE between these two instruments amounts to $1.4 \mathrm{~K}$ (Fig. 9a).

\subsection{Atmospheric effects regarding sealed and non-sealed surfaces}

Now, we use the atmospheric path length as a representative parameter of LOS geometry variability in order to discuss atmospheric effects for different urban surface types. The fictitious experimental setup and results presented in Sect. 4.3 reveal that the atmospheric correction is sensitive to the surface-to-air temperature difference. Hence, we discuss atmospheric effects at 12:00 for two surface types derived from image masks. These are sealed surfaces (roofs, walls and roads) in order to account for hot surfaces and 108 selected tree crowns, because we expect that tree surface temperature is close to air temperature (Oke, 1987; Leuzinger et al., 2010).

The atmospheric effects $\left(T_{\mathrm{b}}^{\mathrm{cam}}-T_{\mathrm{b}}^{\mathrm{MLOS}}\right)$ relating to sealed surfaces are shown in Fig. 10a. The atmospheric correction clearly depends on the distance between TIR camera and sealed surface. If we use the SLOS method, this effect produces a strong bias (Fig. 10c). With distances less than $230 \mathrm{~m}$, the SLOS method produces a warm bias (up to $1.5 \mathrm{~K}$ ) and a cold bias (up to $4.3 \mathrm{~K}$ ) if the distance is more than $230 \mathrm{~m}$. The atmospheric effects relating to tree crowns are shown in Fig. 10b and d. The dependence on path length 

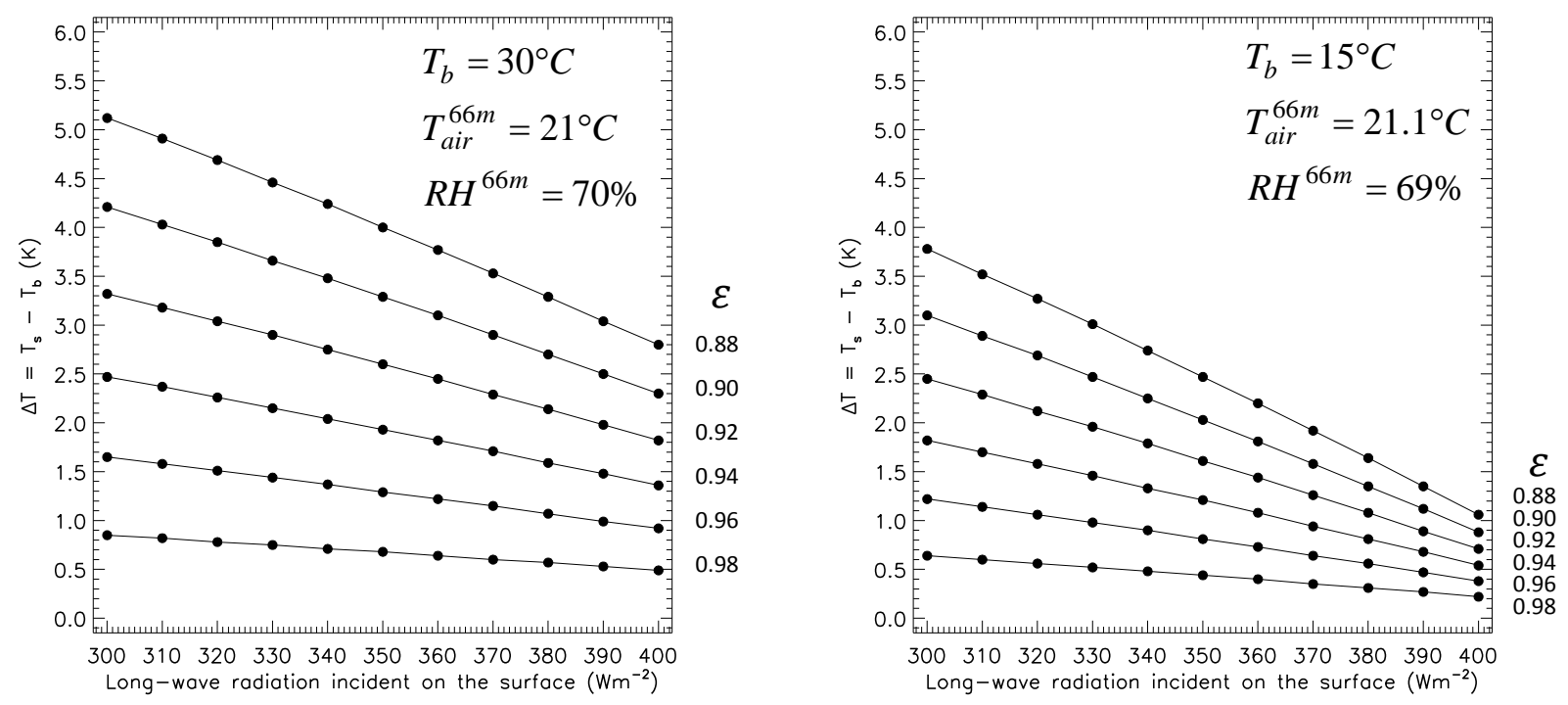

Fig. 11. Difference between surface temperature $\left(T_{\mathrm{S}}\right)$ and surface brightness temperature $\left(T_{\mathrm{b}}\right)$ as a function of surface emissivity and reflected long-wave radiation incident on the surface for (a) hot surfaces (daytime) and (b) cold surfaces (night-time).

is present, but $T_{\mathrm{b}}^{\mathrm{cam}}-T_{\mathrm{b}}^{\mathrm{MLOS}}$ is in the range of $1 \mathrm{~K}$. The slope of a linear regression between atmospheric effect and atmospheric path length (Fig. 10b) is only $-0.001 \mathrm{~K} \mathrm{~m}^{-1}$. This value for tree surfaces shows that small deviations for LOS geometry parameters due to missing information in the DSM are negligible. The SLOS method produces only a small warm bias of up to $0.2 \mathrm{~K}$ and the cold bias is up to $0.3 \mathrm{~K}$ (95\% percentile) (Fig. 10d). The latter quantification is based on the $95 \%$ percentile data, because the extreme values are prone to represent non-tree surfaces due to falsely classified pixels during the creation of the tree crown mask by visual interpretation of photographs and TIR imagery.

\subsection{Error analysis with respect to surface emissivity}

In order to estimate the discrepancy ( $\Delta T=T_{\mathrm{S}}-T_{\mathrm{b}}$ ) between real (thermodynamic) surface temperature $\left(T_{\mathrm{S}}\right)$ and surface brightness temperature $\left(T_{\mathrm{b}}\right)$ we calculated two (daytime and night-time) at-sensor radiances for $\varepsilon=1.0$ and median LOS parameters. Then we searched for the $T_{\mathrm{s}}$, which produces the same at-sensor radiances under consideration of surface emissivity values ranging from 0.88 to 0.98 . One issue that can offset the temperature effects of emissivity is reflected long-wave radiation incident on the surface. This amount could be essential if we consider that urban surfaces receive long-wave radiation emitted from other urban surfaces and not only from the relatively cold sky. We varied the amount of long-wave radiation between 300 and $400 \mathrm{~W} \mathrm{~m}^{-2}$. Surface reflectivity was assumed to equal one minus the emissivity. The results are presented in Fig. 11. For the daytime situation $\left(T_{\mathrm{b}}=30^{\circ} \mathrm{C}\right)$ the maximum $\Delta T$ amounts to $5.1 \mathrm{~K}$ for $\varepsilon=0.88$ and $300 \mathrm{~W} \mathrm{~m}^{-2}$. The error decreased to $0.5 \mathrm{~K}$ if the emissivity is increased to 0.98 and long-wave radiation to a value of $400 \mathrm{~W} \mathrm{~m}^{-2}$. For the night-time situation $\left(T_{\mathrm{b}}=15^{\circ} \mathrm{C}\right)$ the maximum $\Delta T$ amounts to $3.8 \mathrm{~K}$ and the minimum $\Delta T$ amounts to $0.2 \mathrm{~K}$.

\section{Conclusions}

The study shows that atmospheric correction of TIR imagery of the 3-D urban environment acquired in oblique viewing geometry has to account for spatial variability of LOS geometry. The combination of 3-D city models, DGM data and 3$\mathrm{D}$ computer vision techniques allows a pixel-by-pixel determination of LOS geometry parameters used for atmospheric correction. The magnitude of atmospheric effects varies during a diurnal cycle and amounts up to $6.7 \mathrm{~K}$ (Fig. $7 \mathrm{~b}$, left column). This is particularly noticeable for surfaces having a strong surface-to-air temperature difference, a typical phenomenon for urban environments (Voogt and Oke, 2003). The developed and applied MLOS method reveals that the effects of the atmosphere are not properly corrected, if only the median LOS parameters are taken into account. This leads to errors of up to $3.7 \mathrm{~K}$ during the day (Fig. $7 \mathrm{~b}$, right column) and up to $0.5 \mathrm{~K}$ during the night (Fig. 7 d, right column). An accurate determination of urban surface temperatures via thermal remote sensing is important for sensible heat flux calculations (Voogt and Grimmond, 2000) or the evaluation of surface heat island mitigation measures for instance the conversion of asphalt-covered parking areas to grass-covered ones (Takebayashi and Moriyama, 2009). Atmospheric effects are small for vegetative, shadowed surfaces and trees, but even a $1 \mathrm{~K}$ difference can be important for the study of surface temperature variability in relation to tree species or specific urban habitat (Kjelgren and Montague, 
1998; Leuzinger et al., 2010). The atmospherically corrected TIR data are in good accordance with in-situ surface temperature measurements acquired above one roof inside the FOV. However, the roof selected for in-situ measurements is not strictly homogenous. This leads to spatial variability of surfaces temperature, which is measured by the in-situ pyrometer, but which is not detectable by the geometrical resolution of the TIR image.

The complete atmospheric correction processing chain (encoded in IDL) inclusive the MOD5 simulations needs approximately 1 min computing time on a dual core personal computer. Therefore, a near real-time application of the MLOS atmospheric correction procedure is possible for a TIR image recording frequency lower than $1 \mathrm{~min}$. Further studies will address the estimation of cloud base and horizontal visibility for the atmospheric correction of TIR imagery acquired at cloudy sky days.

Acknowledgements. We would like to thank our colleagues at the Chair of Climatology (Technische Universität Berlin, Department of Ecology) for helping to set up and maintain the TIR camera measurement platform and the meteorological measurement sites, G. P. Anderson and A. Berk for valuable comments on using MODTRAN 5.2 and T. H. Kolbe for making available the 3-D building model dataset.

Edited by: T. von Clarmann

\section{References}

Becker, F. and Li, Z.-L.: Towards a local split window method over land surfaces, Int. J. Remote Sens., 11, 369-393, 1990.

Berk, A., Bernstein, L. S., Anderson, G. P., Acharya, P. K., Robertson, D. C., Chetwynd, J. H., and Adler-Golden, S. M.: MODTRAN cloud and multiple scattering upgrades with application to AVIRIS, Remote Sens. Environ., 65, 367-375, 1998.

Berk, A., Anderson, G. P., Acharya, P. K., Bernstein, L. S., Muratov, L., Lee, J., Fox, M. J., Adler-Golden, S. M., Chetwynd, J. H., Hoke, M. L., Lockwood, R. B., Cooley, T. W., and Gardner, J. A.: MODTRAN5: a reformulated atmospheric band model with auxiliary species and practical multiple scattering options, Soc. Photo-Opt. Instrum., 5655, 88-95, 2005.

Chudnovsky, A., Ben-Dor, E., and Saaroni, H.: Diurnal thermal behavior of selected urban objects using remote sensing measurements, Energ. Buildings, 36, 1063-1074, 2004.

Dash, P., Göttsche, F.-M., Olesen, F.-S., and Fischer, H.: Land surface temperature and emissivity estimation from passive sensor data: theory and practice-current trends, Int. J. Remote Sens., 23, 2563-2594, 2002.

Foley, J. D. and van Dam, A.: Fundamentals of interactive computer graphics, in: The Systems Programming 5 Series, 1 edition, Addison-Wesley Publishing Company, Reading, 1984.

Hoyano, A., Asano, K., and Kanamaru, T.: Analysis of the sensible heat flux from the exterior surface of buildings using time sequential thermography, Atmos. Environ., 33, 3941-3951, 1999.
Jacob, F., Gu, X. F., Hanocq, J.-F., Tallet, N., and Baret, F.: Atmospheric corrections of single broadband channel and multidirectional airborne thermal infrared data: application to the ReSeDA experiment, Int. J. Remote Sens., 24, 3269-3290, 2003.

Kerr, Y. H., Lagouarde, J.-P., and Imbernon, J.: Accurate land surface temperature retrieval from AVHRR data with use of an improved split window algorithm, Remote Sens. Environ., 41, 197209, 1992.

Kjelgren, R. and Montague, T.: Urban tree transpiration over turf and asphalt surfaces, Atmos. Environ., 32, 35-41, 1998.

Kolbe, T. H.: Representing and exchanging 3-D city models with CityGML, in: Lecture Notes in Geoinformation and Cartography, edited by: Lee, J. and Zlatanova, S., Springer, Berlin, 15-31, 2009.

Lagouarde, J.-P. and Irvine, M.: Directional anisotropy in thermal infrared measurements over Toulouse city centre during the CAPITOUL measurement campaigns: first results, Meteorol. Atmos. Phys., 102, 173-185, 2008.

Lagouarde, J.-P., Moreau, P., Irvine, M., Bonnefond, J.-M., Voogt, J. A., and Solliec, F.: Airborne experimental measurements of the angular variations in surface temperature over urban areas: case study of Marseille (France), Remote Sens. Environ., 93, 443462, 2004.

Lagouarde, J.-P., Henon, A., Kurz, B., Moreau, P., Irvine, M., Voogt, J., and Mestayer, P.: Modelling daytime thermal infrared directional anisotropy over Toulouse city centre, Remote Sens. Environ., 114, 87-105, 2010.

Leuzinger, S., Vogt, R., and Körner, C.: Tree surface temperature in an urban environment, Agr. Forest Meteorol., 150, 56-62, 2010.

Masson, V., Gomes, L., Pigeon, G., Liousse, C., Pont, V., Lagouarde, J.-P., Voogt, J., Salmond, J., Oke, T. R., Hidalgo, J., Legain, D., Garrouste, O., Lac, C., Connan, O., Briottet, X., Lachérade, S., and Tulet, P.: The Canopy and Aerosol Particles Interactions in Toulouse Urban Layer (CAPITOUL) experiment, Meteorol. Atmos. Phys., 102, 135-157, 2008.

Meier, F., Scherer, D., and Richters, J.: Determination of persistence effects in spatio-temporal patterns of upward long-wave radiation flux density from an urban courtyard by means of timesequential thermography, Remote Sens. Environ., 114, 21-34, 2010.

Mestayer, P. G., Durand, P., Augustin, P., Bastin, S., Bonnefond, J.-M., Bénech, B., Campistron, B., Coppalle, A., Delbarre, H., Dousset, B., Drobinski, P., Druilhet, A., Fréjafon, E., Grimmond, C. S. B., Groleau, D., Irvine, M., Kergomard, C., Kermadi, S., Lagouarde, J.-P., Lemonsu, A., Lohou, F., Long, N., Masson, V., Moppert, C., Noilhan, J., Offerle, B., Oke, T. R., Pigeon, G., Puygrenier, V., Roberts, S., Rosant, J.-M., Said, F., Salmond, J., Talbaut, M., and Voogt, J.: The urban boundary-layer field campaign in Marseille (UBL/CLU-ESCOMPTE): set-up and first results, Bound.-Lay. Meteorol., 114, 315-365, 2005.

Mitchell, H. B.: Image Fusion. Theories, Techniques and Applications, 1st edition, Springer, Berlin, 2010.

Oke, T. R.: Boundary Layer Climates, 2nd edition, Routledge, London, 1987.

Prata, A. J., Caselles, V., Coll, C., Sobrino, J. A., and Ottlé, C.: Thermal remote sensing ofland surface temperature from satellites: Current status and future prospects, Remote Sens. Rev., 12, 175-224, 1995. 
Price, J. C.: Land surface temperature measurements from the split window channels of the NOAA-7 advanced very high-resolution radiometer, J. Geophys. Res.-Atmos., 89, 7231-7237, 1984.

Richter, R. and Schläpfer, D.: Geo-atmospheric processing of airborne imaging spectrometry data, Part 2: atmospheric/topographic correction, Int. J. Remote Sens., 23, 26312649, 2002.

Rotach, M., Vogt, R., Bernhofer, C., Batchvarova, E., Christen, A., Clappier, A., Feddersen, B., Gryning, S.-E., Martucci, G., Mayer, H., Mitev, V., Oke, T. R., Parlow, E., Richner, H., Roth, M., Roulet, Y.-A., Ruffieux, D., Salmond, J., Schatzmann, M., and Voogt, J.: BUBBLE - an urban boundary layer meteorology project, Theor. Appl. Climatol., 81, 231-261, 2005.

Sands, P. J.: Prediction of vignetting, J. Opt. Soc. Am., 63, 803805, 1973.

Schmugge, T., Hook, S. J., and Coll, C.: Recovering surface temperature and emissivity from thermal infrared multispectral data, Remote Sens. Environ., 65, 121-131, 1998.

Sobrino, J. A., Coll, C., and Caselles, V.: Atmospheric correction for land surface temperature using NOAA-11 AVHRR channel 4 and channel 5, Remote Sens. Environ., 38, 19-34, 1991.
Sugawara, H., Narita, K., and Mikami, T.: Estimation of effective thermal property parameter on a heterogeneous urban surface, J. Meteorol. Soc. Jpn., 79, 1169-1181, 2001.

Takebayashi, H. and Moriyama, M.: Study on the urban heat island mitigation effect achieved by converting to grass-covered parking, Sol. Energy, 83, 1211-1223, 2009.

Voogt, J. A. and Grimmond, C. S. B.: Modeling surface sensible heat flux using surface radiative temperatures in a simple urban area, J. Appl. Meteorol., 39, 1679-1699, 2000.

Voogt, J. A. and Oke, T. R.: Effects of urban surface geometry on remotely-sensed surface temperature, Int. J. Remote Sens., 19, 895-920, 1998.

Voogt, J. A. and Oke, T. R.: Thermal remote sensing of urban climates, Remote Sens. Environ., 86, 370-384, 2003.

Weng, Q. H.: Thermal infrared remote sensing for urban climate and environmental studies: methods, applications, and trends, ISPRS J. Photogramm., 64, 335-344, 2009.

Yang, L. and Li, Y.: City ventilation of Hong Kong at no-wind conditions, Atmos. Environ., 43, 3111-3121, 2009. 